\title{
Energy and nutrient intake of triathletes. Do they meet current recommendations?
}

\author{
I. Alaunyte ${ }^{1}$ and C. F. Talbot ${ }^{1}$ \\ ${ }^{1}$ School of Health Sciences, Liverpool Hope University, Liverpool L16 9JD, UK
}

Triathlon involves three endurance events of swimming, cycling and running. The Olympic or classic triathlon race consists of a $1 \cdot 5$ $\mathrm{km}$ swim, a $40 \mathrm{~km}$ bike ride and a $10 \mathrm{~km} \mathrm{run}^{(1)}$. Many recreational athletes participate in triathlon not for the competition but for fitness and health benefits, weight loss and social reasons. Adequate nutrient intake is important not only to optimise performance during competition but also to support training regimes ${ }^{(2)}$. The basis of adequate nutrient intake is a healthy and balanced diet, therefore, recommendations for recreational athletes is to consume a diet, which follows current dietary recommendations for general population $^{(3,4)}$.

Participants (n 32) were recruited from a triathlon club based in the North West. A short self-report questionnaire was used to collect participants' characteristics including gender, age, weight, and height. Dietary habits were assessed using 3-day food diaries and analysed by Microdiet. Exercise levels were assessed using 3-day exercise records. The energy and nutrient intakes were compared to national recommendations ${ }^{(3,4)}$ using one-sample t-test.

The study consisted of 19 female and 13 male triathletes, aged 33 years (SD 11.6) with BMI of 21 (SD 3.2). Male participants were engaged in 3-6 hours of cardiovascular exercise during a study period of 3-days, whilst female athletes completed 1-4 hours of cardiovascular exercise.

Food diaries revealed that both gender triathletes achieved recommended levels of energy intake. Female athletes consumed significantly lower amount of carbohydrate and dietary fibre when compared to the recommendations, whilst the levels of non-milk extrinsic sugars (NMES) was significantly higher. Male participants achieved their carbohydrate intakes, however, protein, total fat and NMES intakes were too high. In terms of micronutrients, only dietary iron intake in female triathletes' diet was significantly lower when compared to the current recommendation. In fact only $10 \%$ of female participants met reference nutrient intake (RNI) for dietary iron.

\begin{tabular}{|c|c|c|c|c|c|c|c|c|}
\hline \multirow[b]{3}{*}{ Nutrient } & \multicolumn{4}{|c|}{ Females $(n$ 19) } & \multicolumn{4}{|c|}{ Males $(n$ 13) } \\
\hline & \multicolumn{2}{|c|}{ Present study } & \multirow{2}{*}{ DRVs } & \multirow{2}{*}{$P$ value } & \multicolumn{2}{|c|}{ Present study } & \multirow{2}{*}{ DRVs } & \multirow{2}{*}{$P$ value } \\
\hline & Mean & SD & & & Mean & SD & & \\
\hline Energy (kcal/day) & 2439 & 1286 & 2415 & NS & 2771 & 544 & 2862 & NS \\
\hline Carbohydrate ( $\%$ TEI) & $39 \cdot 2$ & $13 \cdot 3$ & 47 & $0 \cdot 020$ & $46 \cdot 5$ & $9 \cdot 6$ & 47 & NS \\
\hline Dietary fibre (g/day) & $12 \cdot 9$ & $5 \cdot 4$ & 18 & $0 \cdot 001$ & $12 \cdot 0$ & $4 \cdot 2$ & 18 & 0.001 \\
\hline NMES (\% TEI) & $17 \cdot 2$ & 11.8 & 10 & $0 \cdot 001$ & $22 \cdot 1$ & $9 \cdot 1$ & 10 & $0 \cdot 001$ \\
\hline Protein ( $\%$ TEI) & $17 \cdot 4$ & $5 \cdot 6$ & 15 & NS & $17 \cdot 6$ & $3 \cdot 3$ & 15 & 0.015 \\
\hline Fat $(\%$ TEI $)$ & $37 \cdot 6$ & $12 \cdot 9$ & 33 & NS & $37 \cdot 5$ & $6 \cdot 9$ & 33 & 0.037 \\
\hline Saturated fats ( $\%$ TEI) & $13 \cdot 6$ & $14 \cdot 1$ & 10 & NS & 11.6 & $3 \cdot 4$ & 10 & NS \\
\hline Vitamin C (mg/day) & 64.9 & $36 \cdot 9$ & 40 & $0 \cdot 001$ & $247 \cdot 0$ & 129.9 & 40 & 0.001 \\
\hline Sodium (mg/day) & 3988 & 1064 & 1600 & $0 \cdot 001$ & 3924 & 1439 & 1600 & $0 \cdot 001$ \\
\hline Calcium (mg/day) & $792 \cdot 2$ & $322 \cdot 0$ & 700 & NS & $914 \cdot 2$ & 389 & 700 & NS \\
\hline Iron (mg/day) & $11 \cdot 9$ & $5 \cdot 1$ & $14 \cdot 8$ & $0 \cdot 023$ & $14 \cdot 9$ & $5 \cdot 0$ & 8.7 & 0.001 \\
\hline Magnesium (mg/day) & $253 \cdot 2$ & $75 \cdot 1$ & 270 & NS & $290 \cdot 0$ & $72 \cdot 2$ & 300 & NS \\
\hline Zinc (mg/day) & $10 \cdot 3$ & 3.5 & $7 \cdot 0$ & $0 \cdot 001$ & $12 \cdot 2$ & $3 \cdot 8$ & $9 \cdot 5$ & 0.001 \\
\hline
\end{tabular}

Key: DRVs- Dietary Reference Values, TEI - Total Energy Intake, NS - non-significant

In conclusion, the cross-sectional study showed that the diets of triathletes are not well balanced. Whilst the energy and protein intakes are achieved, carbohydrate levels are low, especially for dietary fibre. Female athletes may be also at risk of compromised iron status due to significantly low intakes of dietary iron. Recreational athletes should be better educated on the importance of carbohydrate intake for endurance sport.

1. Bentley DJ, Millet GP, Vleck VE et al. (2002) Sports Med 32, 345-359.

2. Jeukendrup A E (2011) J Sports Sci 29, S91-S99.

3. Department of Health (1991) Dietary Reference Values for Food Energy and Nutrients for the United Kingdom, London: TSO.

4. SACN (2011) Dietary Reference Values for Energy, London: TSO. 